\title{
FATORES RELEVANTES À FORMAÇÃO E MANUTENÇÃO DE COMUNIDADES VIRTUAIS FACILITADORAS DA APRENDIZAGEM
}

\section{Daniela Haetinger*}

RESUMO: Este artigo identifica a emergência das comunidades virtuais no ciberespaço como um fenômeno contemporâneo que amplia as práticas sociais humanas e favorece a aprendizagem; destaca conceitos relativos à dimensão social da aprendizagem, como a colaboração e a cooperação; consolida os resultados de nossa pesquisa sobre os fatores relevantes à formação e ao sucesso de comunidades on-line facilitadoras da aprendizagem.

PALAVRAS-CHAVE: ciberespaço, comunidades virtuais, práticas sociais, aprendizagem, colaboração e cooperação.

ABSTRACT: This paper identifies the emergence of online communities in cyberspace as a contemporary phenomenon that broadens the human social practices and contributes to learning; presents theoretical notions about social learning, such as collaboration and cooperation; consolidates the results of our research about relevant factors to the establishment and success of online learning communities.

KEY-WORDS: cyberspace, online communities, social practices, learning, collaboration, cooperation.

\section{Introdução}

A interação e o convívio em redes de computadores geraram um fenômeno social tipicamente contemporâneo: a emergência das comunidades virtuais. Estes espaços de sociabilidade se efetivam pelo encontro de sujeitos dispostos a compartilhar informações e saberes, suportados pela atual infra-estrutura tecnológica, que oportuniza uma comunicação dinâmica, desterritorializada, livre dos limites impostos pelas noções de tempo e espaço.

As comunidades virtuais popularizaram-se a partir de meados dos anos 90, estando intimamente relacionadas ao advento das novas tecnologias de informação e comunicação. Além de possibilitarem novas formas de convivência por meio da interconexão remota, revelam-se ambientes facilitadores da aprendizagem devido às atitudes colaborativas e cooperativas de seus participantes e aos fluxos de saberes individuais e coletivos que integram.

Hoje, as práticas comunitárias on-line são cada vez mais usuais na perspectiva da Sociedade em Rede (CASTELLS, 1999). Constituem um fenômeno historicamente recente, a ser amplamente explorado como objeto de estudo, se pretendemos compreender os elementos e fatores que favorecem a aprendizagem em espaços virtuais.

O sentido de "virtual" adotado fundamenta-se na definição de Lévy: "É virtual toda entidade 'desterritorializada', capaz de gerar diversas manifestações concretas em diferentes momentos e locais determinados, sem contudo estar ela mesma presa a um lugar ou tempo em particular." (LÉVY, 2000, p. 47)

*Especialista em Informática na Educação e Designer Instrucional, danih@via-rs.net. V.3 $\mathrm{N}^{\mathrm{o}}$ 1, Maio, 2005 
A atualidade da temática em questão, sua estreita relação com o processo de ensino-aprendizagem via redes de computadores, e a carência de dados que contemplassem a realidade brasileira, despertaram nosso interesse em realizar uma pesquisa que evidenciasse respostas para as seguintes questões:

a) Quais os dispositivos de comunicação utilizados nas comunidades virtuais e em que medida eles contribuem com a aprendizagem?

b) Que fatores motivam a participação em comunidades on-line?

c) Quais são os resultados prioritários da participação nessas comunidades?

d) Que fatores são relevantes à formação e manutenção de comunidades virtuais?

A partir de tais indagações, desenvolvemos um estudo específico, investigando os motivos pelos quais a aprendizagem pode ser facilitada no contexto das comunidades virtuais. Elaboramos o presente artigo a fim de consolidar os resultados obtidos, tornando-os acessíveis à comunidade científica, e também para compartilhar algumas análises do referido tema com os demais colegas que participam do debate sobre o uso de novas tecnologias de informação e comunicação como ferramentas de aprendizagem.

\section{Sobre os métodos e o universo da pesquisa}

A pesquisa foi desenvolvida no segundo semestre de 2004. Em sua primeira etapa, dedicamo-nos a uma revisão bibliográfica voltada à identificação do ciberespaço, dos dispositivos de informação e comunicação vigentes no universo on-line e suas implicações na dimensão social humana; à apresentação de teorias subsidiadoras da aprendizagem, ressaltando-se a influência das práticas sociais, da colaboração e da cooperação no processo de construção do conhecimento; à caracterização das comunidades virtuais como ambientes potencializadores da aprendizagem.

$\mathrm{Na}$ segunda fase do estudo, realizamos uma pesquisa de campo junto a 14 educadores que participavam do Curso de Especialização a Distância em Informática da Educação, promovido pelo Centro Interdisciplinar de Novas Tecnologias na Educação da Universidade Federal do Rio Grande do Sul. Todos os integrantes do universo de pesquisa são professores com formação acadêmica, que têm participado de comunidades virtuais nos últimos anos, seja em programas educativos ou em outros tipos de comunidades on-line.

Os participantes responderam a um questionário enviado via e-mail, expressando assim suas opiniões e experiências relacionadas às interações no universo on-line. As questões apresentadas exigiam a atribuição de graus (de 0 a 10) a todas as categorias previstas. Após a obtenção dos dados, os mesmos foram tabulados e analisados, trabalhando-se sempre com a média das respostas obtidas e o respectivo desvio padrão.

\section{Domínios do ciberespaço}

Os atuais sistemas e ferramentas de informação e comunicação (Internet, Web, correio eletrônico, hipertextos, groupwares, simulações, realidades virtuais, entre outros) possibilitaram a formação de um universo que transcende delimitações de espaço e tempo e abrange um intenso trânsito de informações, a interação entre milhares de indivíduos e a construção e a fruição de saberes individuais e coletivos: o ciberespaço. 
Este ambiente possui alto grau de interatividade e oferece o acesso ilimitado a todo tipo de ferramentas e fluxos de informação e a espaços virtuais que fomentam o convívio e o relacionamento interpessoal, o intercâmbio de conhecimentos, a formação continuada e o aprimoramento de habilidades e competências. Tudo isso em âmbito global e independente das posições geográficas dos atores sociais. Enfim, não podemos negar sua existência mesmo que não seja possível visualizá-lo materialmente ou fixá-lo em qualquer coordenada de espaço e tempo.

Tipicamente descentralizado e interativo, o ciberespaço é hoje o cenário de novas práticas sociais, cognitivas, educacionais, políticas, artísticas, culturais, comerciais, econômicas e administrativas, servindo à organização e/ou articulação de pessoas, conhecimentos, comunidades, instituições, corporações e governos.

São inúmeros os exemplos nesse sentido: empresas e instituições públicas e privadas disponibilizam produtos, serviços e cursos on-line; manifestações políticas visam à mudança de valores e condições sociais vigentes; cidades são gerenciadas; comunidades virtuais ampliam-se, fomentando o relacionamento social, temático e profissional, a pesquisa e a formação pessoal.

Segundo Alava (2002), o ciberespaço ultrapassa o âmbito das ferramentas de comunicação e tende a ser um ambiente de "a inovação e a colaboração social" pela diversidade de recursos reunidos neste meio. Sujeitos das mais variadas partes do planeta e faixas etárias, dedicados a qualquer tipo de atividade, estão co-atuando nesse universo e formando redes de relacionamento e colaboração, verdadeiras comunidades virtuais. Através da comunicação on-line, dissemina-se a primeira prática social desterritorializada e em grande escala da história humana, formada por vínculos interpessoais seletivos e interesses comuns.

Nos últimos 10 anos, a interconexão entre cidadãos de diferentes nacionalidades, territórios e experiências, tornou-se uma prática usual sob a forma de comunidades virtuais, deflagrando assim a emergência do Espaço do Saber, uma dimensão social que "incita a reinventar o laço social em torno do aprendizado recíproco, da sinergia das competências, da imaginação e da inteligência coletiva” (LÉVY, 2003, p. 26).

\section{A noção de comunidade virtual e a dimensão social da aprendizagem}

Howard Reinhold foi o primeiro autor a difundir o conceito de comunidade virtual, em 1993, caracterizando-a como uma agregação cultural formada pelo encontro sistemático de determinado grupo de pessoas no ciberespaço. Este tipo de comunidade sustenta-se pela co-atuação de indivíduos que compartilham valores, interesses, metas e posturas de apoio mútuo, através de interações no universo on-line.

A própria definição de comunidade (muito anterior à sociabilidade nas redes de computadores) expressa um tipo de articulação coletiva bem mais complexo do que o simples somatório de ações individuais. Designa o compartilhamento de experiências, expectativas, discursos, valores, procedimentos e interesses, enfatizando o senso de integração entre determinado grupo de indivíduos.

Mesmo mantendo a essência da vida comunitária, as práticas sociais em meios virtuais diferenciam-se em alguns aspectos daquelas típicas do plano material. Nas 
relações baseadas em espaços territoriais, geralmente o contato físico está em primeiro plano e fornece o impulso para a efetivação das trocas interpessoais. Já nas comunidades on-line, as pessoas aproximam-se basicamente pelos seus interesses e progressivamente passam a sistematizar suas interações.

Sendo assim, a dinâmica das comunidades virtuais deflagra o estágio de um processo histórico de "desvinculação entre localidade e sociabilidade na formação de uma comunidade: novos padrões, seletivos, de relações sociais substituem as formas de interação humana territorialmente delimitadas" (CASTELLS, 2003, p.98).

Castells (2003) também define que as comunidades virtuais têm origens comuns aos movimentos da contracultura e aos estilos alternativos de vida que influenciaram a organização social desde os anos 60 . Os primeiros usuários das redes computadorizadas, seus ideais democráticos e desejo de liberdade comportamental - aspectos típicos daquele momento histórico - inspiraram a prática da interconexão on-line.

Atualmente, a participação nessas comunidades ainda tende a ser espontânea, voluntária e influenciada por aspirações pessoais. Expressa o que seus membros estão dispostos a compartilhar, a ensinar e a aprender. Esta disposição dos participantes gera uma atitude pró-ativa, colaborativa e cooperativa, pois eles se encontram por vontade própria e para interagir a partir de suas afinidades.

As trocas estabelecidas representam uma grande oportunidade para uns aprenderem com os outros (de modo colaborativo) ou a partir de ações coordenadas (cooperativamente), seja em ambientes informais (onde participam livremente, sem contar com mediação ou liderança formal e institucional), ou formais (com mediadores vinculados a instituições e corporações).

A colaboração interpessoal e o uso de ferramentais digitais colaborativas incentivam e qualificam as discussões pela grande variedade simbólica e ideológica veiculada entre os integrantes de um grupo. A diversidade e a espontaneidade das observações, interpretações, hipóteses e dos pontos de vista, promovem um intenso diálogo e abre espaço para a manifestação e a apreciação das subjetividades. A interconexão e o diálogo geram a inclusão social, a reciprocidade, a solidariedade e a democracia, em oposição ao genuíno individualismo propagado ao longo de décadas nas sociedades capitalistas.

A recíproca entre os participantes é uma característica recorrente nas práticas sociais on-line. Lévy (2000) reitera a existência de uma atitude moral de reciprocidade nas comunidades virtuais, pois o intercâmbio de discursos e mensagens entre os membros acontece pelo desejo (implícito ou explícito) que cada um tem de aprender com o(s) outro(s). E, ao obter uma informação com outrem, somos impelidos a retribuir esse "ganho", oferecendo algo em troca.

Cabe ressaltar que não são as atividades colaborativas em si que sustentam uma comunidade de aprendizagem, mas sim o espírito de colaboração, como Palloff e Pratt definem $(2002,2003)$. Através do respeito e da autonomia, honestidade, franqueza e correspondência mútuas, os participantes exploram diferentes perspectivas e habilidades, constroem uma identidade comum, desenvolvem o pensamento crítico, compartilham e criam significados, refletem sobre suas ações e concretizam seus aprendizados. "A interação e o retorno que os outros dão ajudam a determinar a 
exatidão e a pertinência das idéias. Colaboração, objetivos comuns e trabalho de equipe são forças poderosas no processo de aprendizagem" (PALLOFF e PRATT, 2002, p. 38).

Ainda no século passado, Vygotsky (1998) já reconhecia que a colaboração entre os pares é uma ação imprescindível para a aprendizagem, porque expressa a heterogeneidade presente nos grupos e ajuda a desenvolver estratégias e habilidades de solução de problemas, em virtude do processo cognitivo implícito na interação e comunicação.

Esse compartilhamento de ações implica na construção de conhecimentos, pois reúne diferentes ritmos, experiências, trajetórias, contextos, valores e níveis de conhecimento, possibilitando a ampliação das capacidades e habilidades individuais. "[...] Diversidade de níveis intelectuais constitui uma condição importante da atividade coletiva" (VYGOTSKY apud VEER e VALSINER, 2001, p.88); portanto, contribui com a aprendizagem.

Além da colaboração, as ações e atitudes cooperativas podem ser identificadas na dinâmica das comunidades on-line. Tjara (2002) relata que a cooperação requer a ocorrência dos seguintes elementos entre os participantes de um grupo: objetivos e valores comuns, trabalho coletivo, respeito mútuo, tolerância, interdependência, negociação constante, saber conviver e lidar com as diferenças e com a liderança situacional (variável conforme a personificação dos ideais coletivos vigentes entre os membros). Nesse sentido,

As comunidades virtuais pressupõem cooperações, estimulam a participação, o desenvolvimento compartilhado. Elas negam a possibilidade de coerção. Estimulam a troca, respeitando sempre os valores preestabelecidos; prevalece a ação conjunta, estimulando ações espontâneas [...] os desequilíbrios são vistos como oportunidades de construção de novos conhecimentos, os ganhos são recíprocos. (TJARA, 2002, p. 66)

Piaget (1973) identifica a cooperação como uma operação comum por parte de diferentes sujeitos. Este tipo de ação conjunta requer flexibilidade, condutas altruístas, posições não-hierárquicas e respeito mútuo entre os membros de um grupo, além da realização de operações recíprocas, complementares ou correspondentes.

A colaboração e a cooperação manifestam a heterogeneidade presente nos grupos. Pessoas sistematicamente reunidas confrontam e reorganizam seus interesses e saberes a partir das trocas interpessoais, aproveitando a fonte de conhecimento que cada uma representa. Esse procedimento de socialização de informações, atitudes, comportamentos e inteligências variadas, gera uma intensa atividade cognitiva individual, a qual culmina com a aprendizagem.

A noção de partilha de conhecimentos está associada, também, a idéia de que todos os agentes envolvidos no sistema são potencialmente beneficiários e provedores de conhecimentos, e que cada um aprenderá com outros agentes que constituem o sistema e ajudará os outros a melhorar suas competências. Evidentemente, isso não significa que todos os agentes aproveitarão da mesma maneira as oportunidades de aprendizagem que lhes são oferecidas. (DEPOVER et al. In: ALAVA, 2002, p. 157)

O espírito e os procedimentos cooperativos e colaborativos caracterizam a dimensão social da aprendizagem. Pensemos nos sistemas sociais, que integram uma V.3 $\mathrm{N}^{\mathrm{o}} 1$, Maio, 2005 
infinidade de atividades inter-relacionadas e se modificam mutuamente. Da mesma forma, o homem, ao viver na coletividade, interage com seus semelhantes e revê continuamente seus conhecimentos. As relações estabelecidas entre diferentes pessoas e seus respectivos pontos de vista fazem com que cada integrante de um grupo transforme o seu pensamento e construa novos aprendizados.

Maturana $(2001,2003)$ reitera nossa natureza tipicamente voltada ao convívio, à colaboração, cooperação e à aceitação dos demais. O ser humano é um animal colaborador e cooperador por excelência, pois vive em uma rede de relações sociais cooperativas. Esta rede pressupõe a confiança, o respeito e a ausência de dominação e manipulação entre as pessoas. A contínua inter-relação entre os âmbitos biológico, humano e social constitui o fenômeno do conhecimento. $\mathrm{O}$ autor afirma:

O compartilhar é em nós um elemento que pertence à nossa biologia [...] nós pertencemos a uma linhagem na qual se conserva o viver em grupos pequenos em interações recorrentes [...] nas interações, o que existe é um desencadear de transformações estruturais recíprocas no encontro [...] (MATURANA, 2001, p. 93-95)

Henschel (1998, apud NOAKES, 1999) também destaca a dimensão social das atividades cognitivas: "a aprendizagem é fundamentalmente social". Sob esta perspectiva, ela envolve a identidade presente nos grupos e não apenas a aquisição de conhecimentos. Compartilhar valores, opiniões, perspectivas e jeitos de fazer as coisas são elementos potencializadores de uma identidade comum e promovem a aprendizagem dos participantes de uma comunidade prática.

Lévy é outro teórico que indica o convívio, a comunicação e a atividade conjunta ou compartilhada como fatores relevantes à cognição: "[...] toda relação humana implica um aprendizado. Pelas competências e conhecimentos que envolve, um percurso de vida pode alimentar um circuito de troca, alimentar uma sociabilidade de saber" (LÉVY, 2003, p. 27). As pessoas são sempre fontes de conhecimentos (independente de seu grau de instrução formal ou status social), e as relações interpessoais representam oportunidades para que umas aprendam continuamente com as outras.

Essa estreita correlação entre sociabilidade, colaboração, cooperação e aquisição de conhecimentos nos leva a compreender as comunidades on-line como ambientes potencializadores da aprendizagem. Elas seguem o princípio da reciprocidade, agrupam membros pró-ativos, autônomos e dispostos a compartilhar e construir conhecimentos a partir de posturas colaborativas e de ações cooperativas. A dinâmica desses ambientes expressa necessidades genuinamente humanas: vida em grupo, comunicação, ajuda mútua, construção e compartilhamento de significados, colaboração e cooperação, gerando novas formas de produção intelectual e de circulação do conhecimento.

\section{Resultados da pesquisa}

a) Quanto aos dispositivos de comunicação

O correio eletrônico é o dispositivo mais utilizado nas comunidades virtuais, ainda que seja uma ferramenta assíncrona e, por isso, menos ágil em termos de simultaneidade da comunicação. Quanto ao grau de utilização, os hiperdocumentos ficaram em segundo lugar, seguidos pelo chat e pelas transmissões e recepções de vídeo. Os dispositivos 
menos utilizados são: simulações, escrita colaborativa, tele e videoconferências, transmissões e recepções de áudio, jogos e RPG's.

Curiosamente, os dispositivos mais utilizados não correspondem àqueles considerados mais favoráveis à aprendizagem (simulações, tele e videoconferências e escrita colaborativa). Já os menos utilizados (transmissão e recepção de áudio, jogos e RPG's) equivalem aos menos favoráveis à aprendizagem.

De modo geral, os participantes consideram todos os dispositivos favoráveis à aprendizagem, o que nos parece bastante pertinente, pois o modo como uma ferramenta é explorada em situações de aprendizagem, é bem mais significativo do que a ferramenta em si. Como Piaget (1977) destaca, "os objetos por eles mesmos não significam nada até fazermos algo com eles."

b) Quanto aos fatores que motivam a participação em comunidades virtuais

A integração de sujeitos em comunidades virtuais é motivada principalmente pela necessidade que eles têm de estabelecer e manter vínculos sociais e afetivos, e pelos seus interesses em ampliar conhecimentos específicos e aprimorar competências e habilidades importantes para o trabalho.

Tais dados reforçam a dimensão social da aprendizagem caracterizada anteriormente. De acordo com Maturana, a aprendizagem é a transformação de cada sujeito em virtude de suas interações recorrentes, as quais se efetivam no âmbito social e "o conhecimento é sempre adquirido na convivência" (MATURANA, 2001, p.123).

Os fatores menos relevantes para a participação em comunidades virtuais são: o cumprimento de tarefas profissionais; a manutenção de relações com instituições, empresas e corporações; o entretenimento; a comercialização de produtos e serviços.

c) Quanto aos resultados da participação em comunidades virtuais

A aprendizagem a partir das trocas estabelecidas pelo grupo é o principal resultado do convívio em comunidades virtuais. Este dado reitera as idéias de Nevado (2004), que ressalta a aprendizagem colaborativa e cooperativa como consequiências do compartilhamento de hipóteses e descobertas presente nos grupos virtuais:

As trocas coletivas nos grupos virtuais constituem algo que elegemos chamar de "construção de uma rede de possíveis" em permanente expansão [...] As descobertas procedimentais (novos possíveis) realizadas pelos aprendizes são socializadas e passam a ser objeto de testagens e ainda novas descobertas [...] o conhecimento nasce do movimento, da dúvida, da incerteza, da necessidade de busca de novas alternativas, do debate, da troca. (NEVADO in FRANCO, 2004, p. 80-81)

Outros resultados da participação em comunidades virtuais são: o conhecimento das experiências e saberes dos demais membros pela observação e pelas falas individuais dirigidas ao grupo, o trânsito em diferentes culturas e a ampliação do convívio social. A diversão e a efetivação de transações comerciais e financeiras apresentam-se como as conseqüências menos recorrentes da vida comunitária no universo on-line. 
Considerando as principais motivações para a participação nesse tipo de comunidade (relacionamento interpessoal, estudo, pesquisa, intercâmbio de conhecimentos, aprimoramento de habilidades e competências), observamos que os resultados da troca interpessoal via redes de computadores englobam aspectos sociais e cognitivos, evidenciando a correlação existente entre a motivação dos participantes e os elementos resultantes de suas interações.

d) Quanto aos fatores relevantes à formação e manutenção de comunidades virtuais facilitadoras da aprendizagem

A revisão teórica (realizada na primeira etapa da pesquisa) propiciou o levantamento dos seguintes fatores relevantes para a formação e manutenção de comunidades virtuais facilitadoras da aprendizagem:

Compromisso, respeito, confiança, solidariedade, condutas altruístas, tolerância, sinceridade/honestidade, adaptabilidade/flexibilidade, autonomia e atitude, autodisciplina, reciprocidade, motivação, disposição para colaborar e cooperar; apreciação das diferenças e aceitação dos demais membros; capacidade crítica e reflexiva; habilidades comunicativas e de diálogo; relacionamento não-hierárquico; condições semelhantes de atuação; intenção explícita de compartilhar valores; vontade de compartilhar competências e habilidades pessoais; objetivos e metas comuns; afinidades e interesses comuns; interdependência entre os participantes; presença de um moderador formal; liderança situacional e informal; delineamento claro das responsabilidades de cada membro; delineamento subtendido das responsabilidades; aceitação das decisões estabelecidas coletivamente; compreensão compartilhada das criações e descobertas efetuadas pelo grupo; criação coletiva de espaços para abrigar as produções dos participantes; comportamento de grupo (papel específico para cada integrante, liderança, especialização das tarefas, gerenciamento de acordos e conflitos); ambiente informal, onde todos se sentem à vontade; ambiente formal que disciplina e limita a atuação dos integrantes.

O universo pesquisado determinou em que medida estes fatores são importantes para a formação e manutenção das comunidades analisadas em nosso estudo. Nenhum fator foi julgado irrelevante pelos entrevistados, comprovando que todos os elementos descritos contribuem de algum modo com o bom andamento das práticas sociais e cognitivas em meios virtuais.

A motivação é o fator considerado mais relevante, seja para a formação ou à manutenção bem-sucedida de uma comunidade virtual facilitadora da aprendizagem (e ressaltamos que bem-sucedida se refere à continuidade das trocas interpessoais). Também em ambos os casos, a presença de um moderador formal é um elemento menos importante. No entanto, a disposição para colaborar e cooperar, a compreensão compartilhada das criações e descobertas efetuadas pelo grupo e o compromisso estabelecido entre os membros, constituem fatores extremamente relevantes.

Especificamente para a formação, destacam-se ainda: as metas, os objetivos, as afinidades e os interesses comuns, o compartilhamento de competências e habilidades pessoais e a intenção explícita de agregar valores. Já quanto à manutenção, outros fatores que influem positivamente são: a apreciação das diferenças e aceitação dos demais membros, a autodisciplina, a criação coletiva de espaços para abrigar as produções dos participantes e as habilidades comunicativas e de diálogo.

\section{Conclusões}

Os membros de uma comunidade on-line acessam informações, pesquisam, dialogam, fazem descobertas, ampliam seus laços sociais e afetivos, atuam de modo recíproco e em rede, compartilhando experiências e saberes e construindo significados. 
Interagem socialmente, buscando satisfazer necessidades individuais em torno de objetivos e/ou interesses comuns. Em termos de atitudes políticas, eles articulam suas hipóteses, adotam rituais e regras em suas práticas, baseando-se em relações nãohierárquicas.

A formação e a manutenção das comunidades virtuais ocorre principalmente em virtude da motivação dos participantes, da disposição que cada um tem para colaborar e cooperar, do intercâmbio de suas criações e descobertas e do compromisso estabelecido entre eles. Para a formação, também são relevantes as afinidades, curiosidades ou os objetivos comuns e o desejo de compartilhar competências, habilidades e valores.

Em relação à manutenção bem-sucedida de uma comunidade on-line, destacam-se ainda: a aceitação da diversidade presente no grupo (respeitando-se as diferenças pessoais), a autodisciplina, o saber se comunicar e dialogar, o desenvolvimento coletivo de espaços destinados à produção dos membros.

Conforme a explanação teórica apresentada e de acordo com os resultados da pesquisa, evidenciamos que diversos elementos incidentes nas práticas colaborativas, cooperativas e comunitárias correspondem a componentes facilitadores da aprendizagem. A equivalência entre fatores significativos ao processo de construção do conhecimento e catalisadores das práticas sociais nas redes de computadores comprova que as comunidades virtuais são ambientes potencializadores da aprendizagem.

Usamos o termo potencializadores porque a dinâmica destes ambientes tem o potencial de favorecer a aprendizagem, devido à dimensão social e às trocas estabelecidas pelos participantes. No entanto, é evidente que isso dependerá principalmente da motivação de cada membro para compartilhar e aprender, da qualidade e continuidade das interações, do espírito de colaboração e cooperação vigente, da reciprocidade e da sintonia do grupo.

Entendemos que os conceitos, análises e dados veiculados neste artigo constituem importantes parâmetros para o trabalho de educadores, designers instrucionais e demais profissionais e especialistas envolvidos na criação, fomento ou mediação de ambientes virtuais facilitadores da aprendizagem.

A abordagem do tema proposto será inesgotável até se obtenham respostas e dados mais abrangentes, capazes de revelar todas as variáveis e implicações relativas ao comportamento dos grupos, às formas de sociabilidade, atividades cognitivas e à formação e manutenção de ambientes virtuais que fomentam o convívio e a aprendizagem.

\section{Referências}

ALAVA, Séraphin et alli. Ciberespaço e formações abertas: rumo a novas práticas educacionais. Porto Alegre: Artmed, 2002.

BRUCKMAN, Amy; RESNICK, Mitchel. (1995). The MediaMoo Project: Constructionism and Professional Community. Disponível em http://www.cc.gatech.edu/ asb/papers/convergence.html. Acessado em 08/07/04.

CASTELLS, Manuel. A Sociedade em Rede. São Paulo: Paz e Terra, 1999. 
A Galáxia da Internet: reflexões sobre a Internet, os negócios

e a sociedade. $1^{\mathrm{a}}$ ed. Rio de Janeiro: Jorge Zahar Editor, 2003.

FRANCO, Sérgio R. K. (Org.). Informática na Educação - estudos

interdisciplinares. Porto Alegre: Editora da UFRGS, 2004.

HAETINGER, Daniela. (2005). Comunidades Virtuais: convívio, colaboração e aprendizagem no ciberespaço. $87 \mathrm{f}$. Monografia (Especialização em Informática na Educação) - Centro Interdisciplinar de Novas Tecnologias na Educação, UFRGS, Porto Alegre.

HORD, Shirley M. (1997). Professional Learning Communities: What Are They And Why They Are Important? In: Issues... about change. v.6, $\mathrm{n}^{\circ} 1$, 1997. Sothwest Educational Development Laboratory. Disponível em http://www.sedl.org/change/issues/issues61.html. Acessado em 10/07/04.

LÉVY, Pierre. A Inteligência Coletiva. 4ª ed. São Paulo: Edições Loyola, 2003. Cibercultura. $2^{\text {a }}$ ed. São Paulo: Editora 34, 2000.

MATURANA, Humberto R. Cognição, ciência e vida cotidiana. Belo Horizonte: UFMG, 2001. Formação humana e capacitação. $4^{\mathrm{a} e d}$. Petrópolis:

Vozes, 2003.

NOAKES, Nick. (1999). Collaboration and Community Constituents: an investigation into the key elements that build, nurture and sustain a collaborative learning community in networked spaces. Fourth Annual TCC Online Conference: Best Practices in Delivering, Supporting, and Managing Online Learning. University of Hawaii, 1999.

PALLOFF, Rena M.; PRATT, Keith. Construindo Comunidades de Aprendizagem no Ciberespaço: estratégias eficientes para salas de aula on-line. $1^{\mathrm{a}} \mathrm{ed}$. Porto Alegre: Artmed, 2002.

estudantes on-line. Porto Alegre: Artmed, 2004

. O Aluno Virtual: um guia para trabalhar com

PELlANDA, Nize M. C.; CAMPOS, Eduardo. (Org.). Ciberespaço: um hipertexto com Pierre Lévy. Porto Alegre: Artes e Ofícios, 2000, p.25-52.

PIAGET, Jean. Estudos Sociológicos. Rio de Janeiro: Forense, 1973.

Piaget on Piaget: the epistemology of Jean Piaget. Suíça: Yale University, Media Design Studio, 1977. Documentário.

ROVAI, Alfred P. (2002). Building Sense of Community at a Distance. International Review Research in Open and Distance Learning. Athabasca University, abril, 2002. Disponível em http://www.irrodl.org/content/v3.1/rovai.html. Acessado em 20/10/04.

SARAGINA, Peg. (1999). Creating a Virtual Learning Community. Fourth Annual TCC Online Conference: Best Practices in Delivering, Supporting and Managing Online 
Learning. University of Hawaii, 1999. Disponível em

http://leahi.kcc.hawaii.edu/org/tcon99/papers/saragina.html. Acessado em 23/07/04.

TJARA, Sanmya F. Comunidades Virtuais: um fenômeno na sociedade do conhecimento. $1^{\text {a }}$ ed. São Paulo: Érica, 2002.

VEER, René Van der; VALSINER, Jaan. Vygotsky: uma síntese. $4^{\mathrm{a}}$ ed. São Paulo: Loyola, 2001.

VYGOTSKY, Lev S. Pensamento e linguagem. $2^{\mathrm{a}}$ ed. São Paulo: Martins Fontes, 1998.

WILSON, Brent; RYDER, Martin (s.d.). Dynamic learning Communities: An Alternative to Designed Instructional Systems. University of Colorado at Denver, Storage technology Coporation. Disponível em

http://carbon.cudenver.edu/ mryder/dlc.html. Acessado em 11/07/04.

Copyright 2005. Direitos reservados à autora. 